\title{
A comparison between the National Food Survey and the Family Expenditure Survey food expenditure data
}

\author{
Sophia E Paterakis* and Michael Nelson \\ Department of Nutrition and Dietetics, King's College London, 150 Stamford Street, London SE1 8WA, UK
}

Submitted 17 November 2002: Accepted 24 February 2003

\begin{abstract}
Objective: Household budget surveys (HBSs) have been used to assess nutritional information for epidemiological purposes. The agreement between this information and other comparable data needs to be examined. The aim of this project was to compare household food expenditure data between two British HBSs: the National Food Survey (NFS) and the Family Expenditure Survey (FES).

Design: Household food expenditure data were compared between the NFS and the FES for the years from 1982 to 1993. Differences in expenditure were assessed by year, by household composition, by income group and by region; for trends across time for all households and for regional, household composition and income group variations.

Setting: Great Britain.

Subjects: Approximately 88000 NFS households and 85000 FES households surveyed between 1982 and 1993 were used in this analysis.

Results: Marked differences between the food expenditure data provided by the two surveys were observed. Furthermore, differences in time trends were substantial, which can lead to different conclusions regarding changes in consumption patterns. Conclusions: There is no obvious reason for the differences in household food expenditure between the NFS and the FES. Methodological differences between the two surveys cannot provide a full explanation for these discrepancies. The NFS and FES are now merged into a single survey (the Expenditure and Food Survey). If HBSs are to be used for epidemiological purposes their validity needs to be established.
\end{abstract}

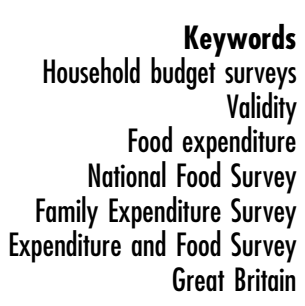

One of the main limitations of nutritional epidemiology is accurate assessment of diet. Many difficulties exist, and the level of accuracy depends on the method used. An important potential source of nutritional information is household budget survey (HBS) data ${ }^{1,2}$. In most European countries HBSs are conducted regularly on a national basis, thus enabling them to be used for within- and between-country comparisons of nutrient intake patterns. Furthermore, the availability of detailed food acquisition data (and hence the low cost of data collection for epidemiological analyses) is a major advantage compared with other methods of obtaining nutritional data. Thus, HBSs can be used as an important tool for monitoring nutritional intakes in European countries. In the UK, the National Food Survey (NFS) and the Family Expenditure Survey (FES) are two independent HBSs that were conducted concurrently on nationally representative samples until 2001.

The $\mathrm{NFS}^{3}$ began in 1940 and achieved national coverage in 1950 . The NFS was conducted annually by the Ministry of Food or the Ministry of Agriculture, Fisheries and Food or the Department of Environment, Food and Rural Affairs until 2001. It was a continuous survey of a nationally representative sample of households in England, Scotland and Wales, gathering information on expenditure and quantities of domestic food acquisitions. Until 1983 the sampling frame was the Electoral Register; subsequently, the small user Postcode Address File (PAF), supplied by the Post Office, was used. The sample design was a threestage stratified random sample. Local authority districts were selected first, then Postal Sectors and lastly individual addresses. Fieldwork was conducted throughout the year (except at Christmas).

The FES $^{4}$ began in 1957 and was also conducted annually until 2001. It was conducted by the Department of Employment until 1989, and thereafter by the Office of National Statistics. It used a nationally representative sample of households in England, Scotland, Wales and Northern Ireland. Until 1985 the sampling frame was the Electoral Register. Sampling used a four-stage stratified rotating design. Thereafter, the FES used the PAF. Postal Sectors were selected randomly after stratifying for region, 
area type, proportion of owner-occupiers and proportion of renters. Fieldwork was conducted throughout the year (except at Christmas).

Both surveys obtained a nationally representative sample of around 7000 households per year. The NFS contained information on quantities and expenditure on household food acquisitions, while the FES contained information only on expenditure. Information was gathered for 7 days for the NFS and 14 days for the FES. In the NFS, diaries of the amount and cost of food acquisitions were completed by the household member mostly responsible for domestic arrangements. In the FES, all household members aged 16 years and over filled in diaries of all expenditure, but amounts of food were not recorded. Additionally, there were some important differences in the information gathered in the two surveys. There were approximately 220 food groups in the NFS but only about 60 in the FES (the numbers varied slightly over the 12 years of the survey analysed in the present report). Before 1992, the NFS did not include information on foods bought and consumed outside the home, nor on soft drinks, sweets or alcoholic beverages. The NFS included information on foods acquired for free, whereas the FES did not. Furthermore, the NFS gathered details concerning the presence of household members and visitors at mealtimes, together with a description of the type of food served. Such information was not included in the FES. In addition, the NFS provided data on nutrient consumption, whereas the level of detail in the FES data was not sufficient to undertake nutrient calculations. Finally, households participating in the NFS received no payment, while in the FES there was a payment for each household member who satisfactorily completed a diary.

The HBS is a potentially important source of nutritional epidemiological data. The aim of the present study was to explore the nature of the errors that might arise when HBS data are used for nutritional surveillance (monitoring of consumption against absolute standards over time) and for measures relating to aetiology (ecological studies comparing relative intakes between subgroups defined by region or by household characteristics, or across time). In trying to answer these questions, we compared household food expenditure data from the NFS and the FES.

\section{Method}

Data on 87964 NFS households and 84571 FES households surveyed between 1982 and 1993 were included in the present analysis. Data were obtained from the Data Archive based in the University of Essex. SAS software was used for analysing the datasets. Analysis was conducted on MIMAS (Manchester Information \& Associated Services) based at the University of Manchester. For this comparison, Northern Irish households were excluded from the FES data.
Households were categorised according to household composition, income group and region. Table 1 shows the number of households in the 12 years analysed, the percentage of each type of household in each survey, and the mean ages of the adults and children in 11 household composition groups. Separate categories were defined for households where men were over 65 and women were over 60 years of age. The samples in the two surveys were similar. Percentages in the different household groups differed between the two surveys by not more than $2.1 \%$ (single younger males). The mean ages of the adults and children for each category were similar in the NFS and the FES. Because $n$ is large, statistically significant differences were found for four groups (unpaired $t$-test), all in the older age categories. The mean ages, however, were within one year of each other in every household group. None of these differences is likely to be of physiological significance and they were not taken into account in the analyses.

Income data in the NFS were reported as 'total weekly net family income', whereas the FES values were for 'gross total household income'. In order to make comparisons between surveys, households were categorised according to income group by ranking the samples from each year of each survey and grouping into fifths of the distribution.

Regional differences in reported expenditures were compared between surveys for 10 standard regions: Wales, Scotland, North, Yorkshire and Humberside, North West, East Midlands, West Midlands, South West, East Anglia, and London and the rest of the South East.

Foods in the two surveys were aggregated to yield comparable food groups. The food groups are listed in Table 2. Between 1982 and 1991, the NFS did not obtain information on sweets, soft drinks and alcoholic beverages, nor on foods bought and consumed outside the home. These foods have therefore been excluded from the analysis. Expenditure on food was adjusted for inflation using the Retail Price Index (RPI) ${ }^{5}$, in order to facilitate comparisons over time. Expenditure in each aggregated food group from each survey was standardised to June 1993 prices by multiplying using a food-group-specific factor calculated by dividing the RPI for June 1993 by the RPI for June from each of the corresponding earlier years.

Although food expenditure data from the NFS and the FES did not show a normal distribution, for reasons of comparability with the published data, means of food expenditure were used to assess the differences between the surveys. Furthermore, means were preferred to medians as there were some food groups for which the median was zero (where fewer than $50 \%$ of households had purchased that particular item).

Differences between the two surveys were assessed either by calculating the difference between the inflationadjusted expenditures or by calculating log \% difference (TJ Cole, personal communication), where log \% difference $=100 \times \log _{\mathrm{e}}(\mathrm{NFS})-100 \times \log _{\mathrm{e}}(\mathrm{FES})$. 
A positive value indicates higher levels of expenditure in the NFS. The means from each survey by year, by household composition, by income group or by region were compared using paired $t$-tests.

To assess if trends across time were similar in the two surveys, linear regression across years was used ${ }^{6}$. The slopes from the NFS and the FES were estimated for total food expenditure and for each aggregated food group. These slopes were compared using Bland's method ${ }^{7}$ :

$$
t=\frac{\text { slope }_{\mathrm{NFS}}-\text { slope }_{\mathrm{FES}}}{\sqrt{\mathrm{SE}_{\mathrm{NFS}}^{2}+\mathrm{SE}_{\mathrm{FES}}^{2}}}
$$

where SE is standard error.

Further analyses were conducted in order to assess regional, household composition and income group variations between the two surveys. Analysis across years was conducted to see if the trends across years for a given region, household composition or income group were similar in both surveys. For this analysis, linear regression across years was used to determine the slopes from each survey for each of the subgroups. Paired $t$-tests were used to examine the differences between the slopes across years for total food expenditure and for individual food groups. Finally, to minimise sampling errors, three years of data from each survey were added together. Thus, data were combined from 1982 through 1984, 1985 through 1987, 1988 through 1990 and 1991 through 1993. For each of these year groupings, plots between the NFS and FES total food expenditure were used to look at where each survey ranks each region, income group and household composition group.

\section{Results}

Figure 1 shows the NFS and FES estimation of total food expenditure (£ per household per week) for the years 1982 to 1993, inflation-adjusted to June 1993 prices. The correlation between the NFS and the FES is almost unity from 1982 to 1993 , but after 1988 there is an increasing divergence between the two surveys.

Figure 2 shows the NFS and FES inflation-adjusted total food expenditure (£ per household per week) by fifths of income distribution. For the bottom and second fifths of income, differences between the NFS and the FES are marked only for the years 1992 and 1993. For the third and fourth fifths of the income distribution, differences between the two surveys increase after 1990. The top fifth shows the greatest differences between the two surveys: reported expenditure is higher in the FES in every year of the analysis and the size of the difference increases after 1988.

Figure 3 shows, for all foods, the year-to-year variation in $\log \%$ difference in inflation-adjusted expenditure between the two surveys. With the exception of 1984, the NFS gave higher estimates of total food expenditure 
Table 2 Log \% difference in inflation-adjusted expenditure between the National Food Survey (NFS) and the Family Expenditure Survey (FES), 1982-93, and difference between slopes (NFS vs. FES) across years (1982-93)

\begin{tabular}{|c|c|c|c|c|c|c|}
\hline \multirow[b]{2}{*}{ Food group } & \multicolumn{3}{|c|}{ Log \% difference } & \multicolumn{3}{|c|}{ Slope across time } \\
\hline & Mean & SD & $P$-value* & Difference $†$ & SE & $P$-value* \\
\hline Total food expenditure & -0.85 & 3.27 & 0.386 & -0.245 & 0.029 & $<0.001$ \\
\hline Fats & 2.60 & 3.47 & 0.025 & 0.004 & 0.002 & 0.987 \\
\hline Fish & 2.20 & 4.22 & 0.097 & -0.003 & 0.003 & 0.164 \\
\hline Meat & 5.34 & 3.21 & $<0.001$ & -0.038 & 0.011 & 0.003 \\
\hline Milk and other dairy products (excluding cheese and butter) & 4.27 & 3.18 & 0.001 & -0.007 & 0.004 & 0.070 \\
\hline Cheese & 10.11 & 3.59 & $<0.001$ & -0.005 & 0.002 & 0.016 \\
\hline Eggs & 10.05 & 6.14 & $<0.001$ & -0.009 & 0.001 & $<0.001$ \\
\hline Cereal & -3.52 & 4.44 & 0.019 & -0.044 & 0.006 & $<0.001$ \\
\hline Potatoes & 7.45 & 2.65 & $<0.001$ & $<0.001$ & 0.002 & 0.536 \\
\hline Vegetables & 7.00 & 3.91 & $<0.001$ & -0.006 & 0.003 & 0.030 \\
\hline Fruits & 1.22 & 3.51 & 0.254 & -0.002 & 0.004 & 0.327 \\
\hline Beverages & 0.79 & 5.81 & 0.646 & -0.015 & 0.002 & $<0.001$ \\
\hline Sugar and sugar products & 0.33 & 5.55 & 0.843 & -0.006 & 0.001 & $<0.001$ \\
\hline Miscellaneous & -36.23 & 6.16 & $<0.001$ & -0.104 & 0.007 & $<0.001$ \\
\hline
\end{tabular}

SD - standard deviation; SE - standard error.

* See text for method of calculation of $P$.

$\dagger$ Difference $=$ difference between slopes (change in expenditure ( $£$ per household per week) per year).

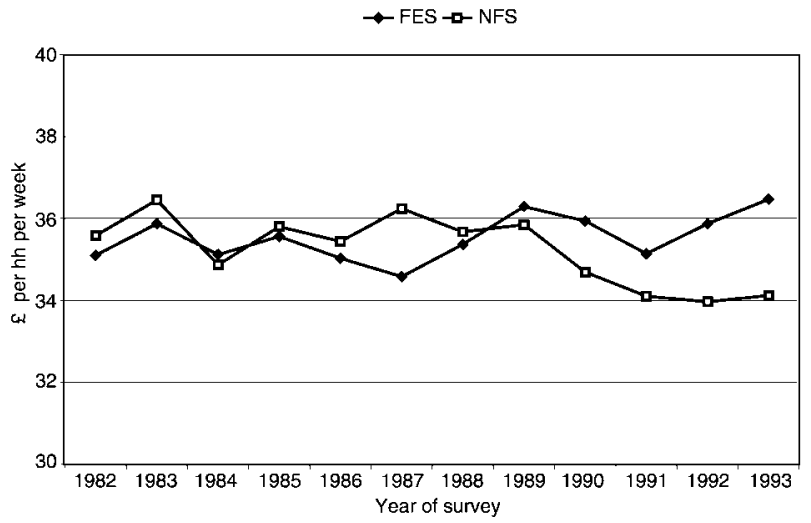

Fig. 1 Inflation-adjusted expenditure (June 1993) on household (hh) food acquisitions ( $£$ per hh per week) according to the National Food Survey (NFS) and the Family Expenditure Survey (FES), 1982-93 (excluding sweets, soft drinks, alcohol and food purchased and eaten away from home; see text for method of adjustment)

from 1982 until 1988. From 1989, the NFS gave lower estimates. The differences ranged from $+5 \%$ in 1987 to $-7 \%$ in 1993 , a $12 \%$ change in a period of six years.

Table 2 shows the mean log \% difference in inflationadjusted expenditure, the standard deviation and $P$-value (paired $t$-test) between the NFS and the FES over the years 1982 to 1993 . The large number of values for $P<0.05$ are the result of the high number of subjects. They are not therefore especially helpful in the interpretation of the findings. Table 2 also shows the differences in slopes across years (1982-93) between the NFS and the FES. Again, although many of the differences are small, they achieve statistical significance because of the large number of observations on which they are based and the ensuing very small standard errors.

Over the 12 years of data, mean log \% differences were low for total food expenditure (less than 1\%). This does not, however, reflect the changes over time shown in Fig. 3. For many individual food groups the average differences were also small (less than 5\%) over the 12-year period. For Meat, Potatoes and Vegetables, however, average reported expenditure between 1982 and 1993 was at least 5\% greater in the NFS, and for Cheese and Eggs, expenditure was over 10\% greater in the NFS. In contrast, reported spending on Miscellaneous foods was 36\% lower in the NFS. The aggregation for the Miscellaneous food group may not be comparable, as this food group contained all the codes from the two surveys that were not included in other food groups. Additionally, in the FES, it included all foods classified as 'undefined'.

Standard deviations were lowest for Potatoes and highest for Eggs, Beverages, and Miscellaneous. This shows that the percentage difference in expenditure estimates from the two surveys varies substantially from year to year.

Statistically significant differences in slopes across years between the NFS and the FES were found for reported total food expenditure and for most food groups apart from Fats, Fish, Milk and other dairy products, Potatoes, and Fruits.

Table 3 shows the mean, standard deviation and $P$-value (paired $t$-test) of the differences in inflation-adjusted expenditures between the NFS and the FES by region, by income group and by household composition. For all three groupings, statistically significant differences were found for Cheese, Eggs, Cereal, and Miscellaneous, while no differences were found for Fish. For the other food groups, differences between surveys varied according to grouping.

If the two surveys provided comparable data, it would be expected that the slopes of the inflation-adjusted expenditure over time would be similar in both surveys for a given region. Paired $t$-tests were carried out to assess the comparability of the slopes for total food expenditure and 

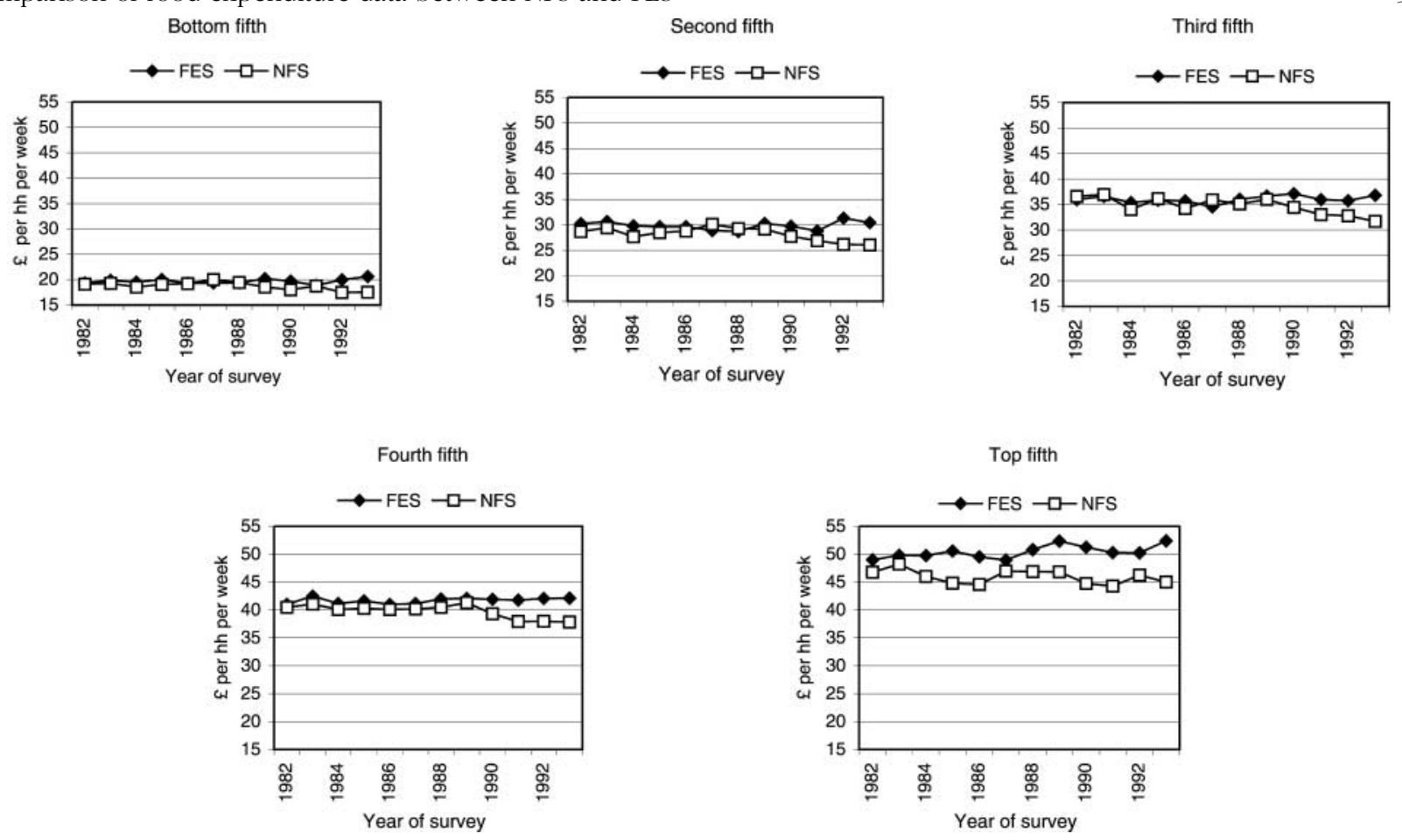

Fig. 2 Inflation-adjusted expenditure (June 1993) on household (hh) food acquisitions (£ per hh per week), by fifth of income distribution, according to the National Food Survey (NFS) and the Family Expenditure Survey (FES), 1982-93 (excluding sweets, soft drinks, alcohol and food purchased and eaten away from home; see text for method of adjustment)

for individual food categories in the two surveys for the 10 regions. Table 4 shows the average difference between slopes in the two surveys across the 10 regions. Differences between surveys were greatest (and most statistically significant) for total food expenditure, Meat, Eggs, Cereal, Beverages, Sugar and sugar products, and Miscellaneous.

Table 4 also shows similar comparisons between slopes over time by five income groups and 11 household composition groups. Differences in slopes by income group and household composition were apparent for total food expenditure and for Eggs, Cereal, Beverages, and Miscellaneous. In addition, differences between slopes were shown across income groups for Fats, Meat, Vegetables, and Sugar and sugar products, and across household composition groups for Cheese.

Figure 4 shows the NFS and FES inflation-adjusted expenditure on household food acquisitions (£ per household per week) for 10 regions for the four combined year groups. In all four year groups, the ordering of regions according to total food expenditure differs substantially between surveys, and variation in ordering changes from one year group to the next. For example, in the NFS in 1985-87, Scotland showed the highest level of expenditure ( $\$ 36.79$ per household per week), whereas in the FES it was third from the bottom with a mean expenditure of $\$ 33.74$. The discrepancy in ranking between surveys (NFS rank minus FES rank) is illustrated for the 10 regions in each of the four year groups in Fig. 5.

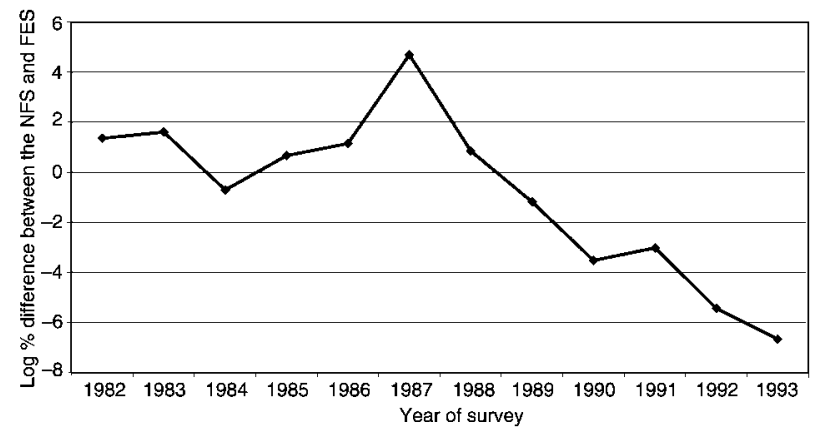

Fig. 3 Log \% difference in inflation-adjusted expenditure (June 1993) on household food acquisitions between the National Food Survey (NFS) and the Family Expenditure Survey (FES), 198293 (excluding sweets, soft drinks, alcohol and food purchased and eaten away from home; see text for method of adjustment)

Wales, for example, is consistently ranked much lower in the NFS than in the FES. In contrast, Scotland is ranked much higher. For some regions, the difference in ranking changed with time. For the North region, for example, the difference changed from +5 in 1982-84 (NFS rank 6, FES rank 1) to -1 in 1991-93 (NFS rank 1, FES rank 2). South West changed from +1 (NFS 3, FES 2) to -5 (NFS 3, FES 8 ). The discrepancies in ranking were found primarily in relation to region. Smaller discrepancies were observed by household composition group (differences between ranks being +3 and -1 ). There were no differences in ranking by income group. 
Table 3 Mean differences in inflation-adjusted expenditure ( $£$ per household per week) between the National Food Survey and the Family Expenditure Survey, by region, income group and household composition

\begin{tabular}{|c|c|c|c|c|c|c|c|c|c|}
\hline \multirow[b]{2}{*}{ Food group } & \multicolumn{3}{|c|}{ By region $(n=10)$} & \multicolumn{3}{|c|}{ By income group $(n=5)$} & \multicolumn{3}{|c|}{$\begin{array}{l}\text { By household } \\
\text { composition }(n=11)\end{array}$} \\
\hline & Difference & SD & $P$-value* & Difference & SD & $P$-value* & Difference & SD & $P$-value* \\
\hline Total food expenditure & -0.30 & 1.25 & 0.461 & -2.07 & 1.38 & 0.028 & -1.41 & 1.27 & 0.004 \\
\hline Fats & 0.02 & 0.06 & 0.244 & -0.04 & 0.02 & 0.011 & -0.02 & 0.05 & 0.129 \\
\hline Fish & 0.03 & 0.06 & 0.224 & -0.08 & 0.08 & 0.071 & -0.03 & 0.07 & 0.270 \\
\hline Meat & 0.44 & 0.42 & 0.010 & -0.11 & 0.26 & 0.412 & 0.06 & 0.27 & 0.460 \\
\hline $\begin{array}{l}\text { Milk and other dairy products } \\
\text { (excluding cheese and butter) }\end{array}$ & 0.17 & 0.09 & $<0.001$ & 0.03 & 0.11 & 0.538 & 0.01 & 0.16 & 0.820 \\
\hline Cheese & 0.12 & 0.04 & $<0.001$ & 0.05 & 0.04 & 0.044 & 0.08 & 0.04 & $<0.001$ \\
\hline Eggs & 0.07 & 0.03 & $<0.001$ & 0.04 & 0.01 & 0.002 & 0.04 & 0.02 & $<0.001$ \\
\hline Cereal & -0.21 & 0.17 & 0.004 & -0.38 & 0.17 & 0.007 & -0.36 & 0.32 & 0.004 \\
\hline Potatoes & 0.11 & 0.11 & 0.010 & 0.08 & 0.08 & 0.086 & 0.04 & 0.06 & 0.069 \\
\hline Vegetables & 0.15 & 0.10 & 0.001 & 0.03 & 0.04 & 0.128 & 0.06 & 0.06 & 0.009 \\
\hline Fruits & 0.04 & 0.10 & 0.290 & -0.14 & 0.10 & 0.033 & -0.02 & 0.10 & 0.540 \\
\hline Beverages & 0.02 & 0.05 & 0.292 & -0.06 & 0.04 & 0.040 & -0.02 & 0.03 & 0.035 \\
\hline Sugar and sugar products & 0.00 & 0.03 & 0.811 & -0.02 & 0.02 & 0.039 & -0.03 & 0.06 & 0.162 \\
\hline Miscellaneous & -1.35 & 0.25 & $<0.001$ & -1.51 & 0.78 & 0.012 & -1.27 & 0.71 & $<0.001$ \\
\hline
\end{tabular}

SD - standard deviation.

${ }^{*} P$-value based on paired $t$-tests.

Table 4 Mean differences between the National Food Survey and the Family Expenditure Survey in terms of slopes* across years, by region, income group and household composition

\begin{tabular}{|c|c|c|c|c|c|c|c|c|c|}
\hline \multirow[b]{2}{*}{ Food group } & \multicolumn{3}{|c|}{ By region $(n=10)$} & \multicolumn{3}{|c|}{ By income group $(n=5)$} & \multicolumn{3}{|c|}{$\begin{array}{l}\text { By household } \\
\text { composition }(n=11)\end{array}$} \\
\hline & Mean & SD & $P$-value† & Mean & SD & $P$-value $†$ & Mean & $\mathrm{SD}$ & $P$-value $†$ \\
\hline Total food expenditure & -0.77 & 0.50 & 0.001 & -0.92 & 0.30 & 0.002 & -0.61 & 0.61 & 0.008 \\
\hline Fats & 0.01 & 0.03 & 0.472 & 0.01 & 0.01 & 0.027 & 0.02 & 0.05 & 0.199 \\
\hline Fish & -0.01 & 0.07 & 0.718 & -0.02 & 0.03 & 0.250 & -0.01 & 0.03 & 0.496 \\
\hline Meat & -0.14 & 0.10 & 0.002 & -0.16 & 0.02 & $<0.001$ & -0.07 & 0.13 & 0.116 \\
\hline $\begin{array}{l}\text { Milk and other dairy products } \\
\text { (excluding cheese and butter) }\end{array}$ & -0.03 & 0.05 & 0.083 & -0.03 & 0.03 & 0.126 & -0.02 & 0.04 & 0.068 \\
\hline Cheese & -0.01 & 0.03 & 0.259 & -0.02 & 0.01 & 0.060 & -0.02 & 0.02 & 0.023 \\
\hline Eggs & -0.03 & 0.02 & 0.005 & -0.02 & 0.01 & 0.001 & -0.02 & 0.02 & 0.017 \\
\hline Cereal & -0.14 & 0.06 & $<0.001$ & -0.16 & 0.08 & 0.011 & -0.11 & 0.09 & 0.003 \\
\hline Potatoes & -0.01 & 0.05 & 0.543 & -0.02 & 0.02 & 0.170 & 0.00 & 0.02 & 0.911 \\
\hline Vegetables & -0.01 & 0.07 & 0.640 & -0.04 & 0.02 & 0.014 & -0.02 & 0.04 & 0.149 \\
\hline Fruits & 0.00 & 0.05 & 0.902 & -0.02 & 0.04 & 0.254 & -0.02 & 0.04 & 0.110 \\
\hline Beverages & -0.05 & 0.03 & $<0.001$ & -0.04 & 0.02 & 0.017 & -0.04 & 0.02 & $<0.001$ \\
\hline Sugar and sugar products & -0.02 & 0.01 & $<0.001$ & -0.02 & 0.01 & 0.022 & -0.01 & 0.02 & 0.199 \\
\hline Miscellaneous & -0.29 & 0.11 & $<0.001$ & -0.37 & 0.17 & 0.008 & -0.29 & 0.23 & 0.002 \\
\hline
\end{tabular}

SD - standard deviation.

${ }^{*}$ Change in expenditure ( $£$ per household per week) per year.

$\dagger P$-value based on paired $t$-tests.

\section{Discussion}

Given that the samples in the NFS and FES are both based on the national $\mathrm{PAF}^{*}$ and are similar in composition (Table 1), there is no obvious explanation for the discrepancies between estimates of total food expenditure, nor for the shift in differences after 1988 (Figs 1 and 3). The simplest explanation is that surveys that concentrate largely on food (the NFS) may produce different results from those that include other items of

*For 1983 and 1984, the FES sampling frame was the Electoral Register. expenditure (the FES). The focus in the NFS on recording amounts of food acquired rather than simply recording expenditure may also have an influence on the differences between the two sets of findings.

The NFS and FES measures of income differ (net in the NFS and gross in the FES). However, it is likely that the categorisation into fifths of the income distribution would produce similar results whichever measure is used. The steady increase in the estimate of the FES expenditure relative to the NFS is apparent in every income band (Fig. 2), and is not, therefore, likely to be a bias related to changes in sampling. There is an estimated 2\% log difference in the mean disposable household incomes of 

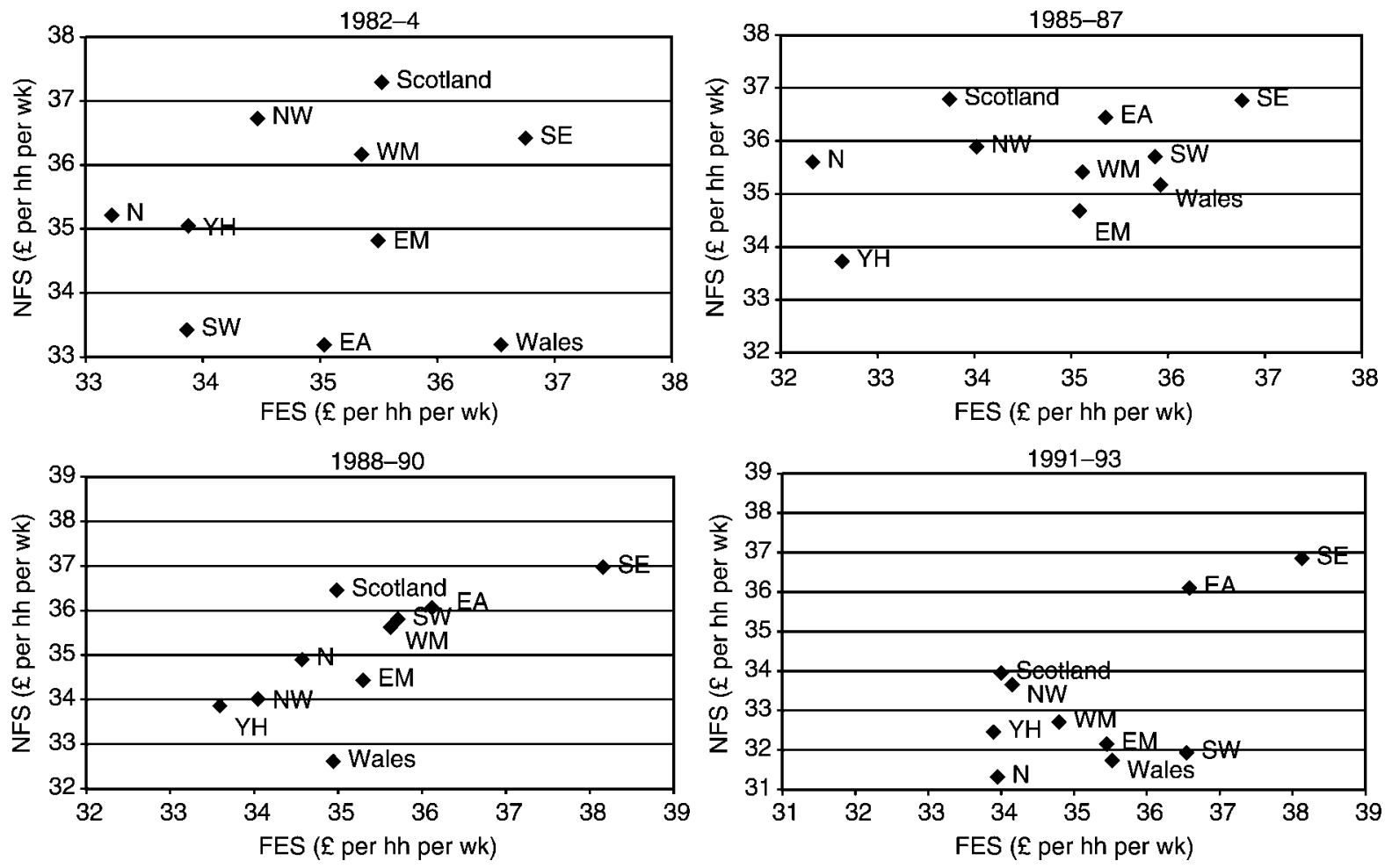

Fig. 4 Inflation-adjusted expenditure (June 1993) on household (hh) food acquisitions ( $£$ per hh per week), by combined year group and by region, according to the National Food Survey (NFS) and the Family Expenditure Survey (FES) (excluding sweets, soft drinks, alcohol and food purchased and eaten away from home; see text for method of adjustment). EA - East Anglia; EM - East Midlands; $N$ - North; NW - North West; SE - South East; SW - South West; WM - West Midlands; YH - Yorkshire \& Humberside

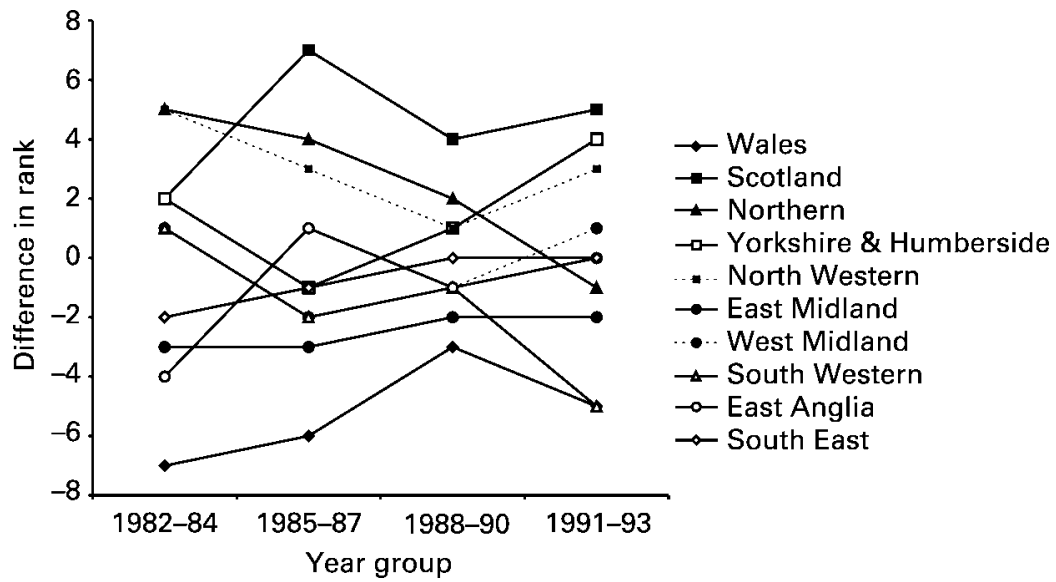

Fig. 5 Differences in rank (National Food Survey minus Family Expenditure Survey) of inflation-adjusted expenditure (June 1993) on total food (£ per household per week) between regions in four year groups (excluding sweets, soft drinks, alcohol and food purchased and eaten away from home; see text for method of adjustment)

the samples in the two surveys (NFS 1993: 282.05 ; FES 1993: £288.44), substantially less than the $7 \% \log$ difference in expenditure on food (Fig. 3). The fact that the difference appears earliest in the highest income group (1983) and latest in the lowest income group (1992) suggests that the phenomenon may be income-related, although the mechanism that could explain such an emergence of differences over time is not apparent.

The mean log \% difference in expenditure between the two surveys over the 12 years of analysis is close to zero
$(-0.85 \%)$ (Table 2$)$. For most food groups, however, the differences were positive and statistically significant, the exceptions being Cereal $(-3.52 \%, P=0.019)$ and Miscellaneous $(-36.23 \%, P=0.000)$. There were also differences in slopes between the two surveys (statistically significant for most food groups) which reflect the divergence between the surveys observed in Fig. 1. For six out of the 14 food groups, statistically significant differences were found between either log \% differences or the slopes across years. While the differences in slope 
are generally small, trend analyses based on the two surveys would lead to different conclusions regarding changes in consumption patterns. Total spending on food (1993 inflation-adjusted) fell in the NFS on average by $£ 0.17$ per year between 1982 and 1993, but rose by per year in the FES. Spending on cereals in the FES rose by approximately $₫ 0.01$ per year over the 12 years, whereas in the NFS expenditure fell by approximately $£ 0.04$ per year. Spending on miscellaneous foods rose by $\$ 0.14$ per year on average in the NFS and by $£ 0.25$ per year in the FES. These changes represent both genuine differences in expenditure by food groups and also differences in categorisation of foods, the FES having the less differentiated coding base and foods that are classed as 'undefined'.

The paired $t$-tests presented in Table 3 show that, with the exception of Fish, all of the food groups showed at least one statistically significant difference between surveys when households were categorised by region, income group or household composition. Regional analysis shows higher NFS expenditure for all food groups except Cereals and Miscellaneous, as was shown for all households (Table 2). In contrast, for income group and household composition analyses, the FES often gave higher estimates of expenditure. In the main, these average differences are very small (although many of them reach statistical significance). These comparisons minimise the effects of sampling variation by combining results across all 12 years.

The differences between trends (slopes) by subgroups across year groups (Table 4 ) are consistent with the results in Tables 2 and 3. Only for Fish, Potatoes and Fruits are the subgroup time trend analyses similar in the two surveys. The most striking differences are revealed in the income group analyses, which reflect the income group contrasts for all foods shown in Fig. 2 (FES expenditure rising more rapidly or NFS expenditure decreasing more rapidly). The income group comparisons are likely to be robust, as the subgroups are based on fifths of the distribution of the primary income variables in the two surveys. This is likely to produce groups that are more comparable than groups based on cut-off points for income, where methodological differences between surveys in the determination of income could result in similar households being classified in different income subgroups. As with comparisons across years for all households, differences between the slopes are negative (apart from Fats); i.e. expenditure was seen to rise more rapidly in the FES than in the NFS.

The differences in ranking by region illustrated in Figs 4 and 5 provides strong evidence that the two surveys are not providing consistent data on food expenditure. The marked differences between surveys in reported food spending in Wales and Scotland are cause for concern. The drift of the North region is also worrying in terms of consistency of reporting. It is not clear why these changes are occurring. There are no obvious differences, for example, in the sampling methodology of the two surveys. The failure of the two surveys to reflect the same changes could in theory lead to misinterpretations of regional dietary trends. These in turn could lead to errors in policy relating to food supply and health promotion resource allocation.

This is the first known published comparison between the NFS and the FES data concerning household food purchases. The two surveys do not show identical trends and differences over time. The differences between the surveys are particularly marked when data are analysed by region. The results from this analysis suggest that differences in coding and associated loss of detail may be one of the reasons for the discrepancies between the two surveys. For example, Vegetables revealed a log \% difference between the NFS and FES of $7 \%$ and the difference between slopes of the change in expenditure (£ per household per week) per year was $-0.006 \%$. The higher expenditure in the NFS may be due to the fact that, in the NFS, 'Leafy salads, fresh' included mixed salad vegetables which are in the Vegetable food group, while in the FES these foods were included in the 'Package and canned foods' which are in the Miscellaneous food group. However, this does not account for the differences in the slopes over time. Furthermore, the present analysis was conducted assuming that the food expenditure data follow a normal distribution, whereas in reality this is not the case. Finally, the inflation adjustment of prices to June 1993 is not robust, as only the June RPI was used for all foods purchased during the year.

The NFS is used as a tool for monitoring nutritional intake patterns in Great Britain. It is used to inform the development of national food policy, to assess if the Dietary Reference Values are met, to evaluate the effect of food fortification policy, to monitor the consumption of additives and contaminants, to look at trends across time, and to explore in ecological studies the relationships between diet and cardiovascular disease ${ }^{8-10}$. The comparison between the NFS and FES expenditure data illustrated in the present study shows important differences in the food expenditure information given by these two surveys that could not be explained by obvious methodological differences between them. If one were to assume that the FES data for home food expenditure in the years 1990-1993 are correct, the measures of home food acquisitions in the NFS would have to be regarded as underestimates. For example, according to a report by the Committee for Medical Aspects of Food Policy (COMA) ${ }^{10}$ based on information provided from the NFS, consumption of total vegetables excluding potatoes has risen between 1970 and 1992 from about 150 to $180 \mathrm{~g}$ person $^{-1}$ day $^{-1}$. FES data show a significantly greater increase each year in mean expenditure on vegetables $(-0.006$, $P=0.03)$, which over a year equates to an average difference in expenditure on vegetables per household of £31.20. If the FES data are correct, NFS data may be 
overstating the protective effect of vegetables in relation to heart disease. This is based on the reasonable assumption that changes in inflation-adjusted expenditure over time will reflect changes in quantities of purchases and levels of consumption. Trends over time of the consumption of vegetables is very important for the COMA report, which gives suggestions on the changes needed in the British diet to minimise the risk of cardiovascular disease, assuming that vegetables are protective against this disease. The NFS data need to be handled cautiously until the reasons for the discrepancies found in this study are resolved.

In most instances, NFS data are relied on for analysis of trends over time (by region, income group, household composition, etc.), but the FES is used to estimate food expenditure and budget shares. This is important in relation to future policy developments regarding Income Support and food subsidies (e.g. food stamps). If the aim were to match expenditure on food in low-income households, the trends by income group reported in the two surveys would lead to higher subsidies using FES data and lower subsidies using NFS data.

In the wider context of the use of HBSs for epidemiological purposes (e.g. in Europe for monitoring nutritional patterns ${ }^{11}$ ), these findings have particular importance. The DAFNE (DAta Food NEtworking) project $^{12,13}$ has used HBS data to produce results from 10 European countries that are comparable in terms of definitions of food groups, occupation, household composition and locality. These counties included Ireland and Greece, for which some of the food items were recorded only as expenditure (these were converted to quantities using price indexes). But the present study has shown that HBSs containing expenditure-only information may give a different picture of a country's dietary patterns compared with a survey that includes data on food quantities as well as expenditure information. In the DAFNE report ${ }^{13}$, for example, Great Britain had lower cheese availability (g person ${ }^{-1}$ day $^{-1}$ ) than Luxembourg, Greece and Norway, and higher availability than Spain and Ireland. If the FES had been used for the DAFNE report, the estimate of cheese consumption in Great Britain would have been 10.11\% lower, and the rank position of Great Britain would have moved close to that of Spain. This raises the question of how comparable information provided by Greece and Ireland are in relation to other national surveys that contain quantity data of each food group. If contrasts between countries are to be made, the potential influence of methodology on outcome needs to be assessed carefully.

\section{Conclusions}

This is the first published paper to report differences in findings between the NFS and the FES. The two surveys do not show identical trends and differences over time. The differences between the surveys are particularly marked when data are analysed by region. In the wider context of the use of HBSs for epidemiological purposes, these findings have particular importance. Surveys that concentrate largely on food may produce different results from those that include other items of expenditure. If contrasts between countries are to be made, the potential influence of methodology on outcome needs to be assessed.

Some preliminary analyses comparing results from HBS data with dietary data collected at the level of the individual have been reported ${ }^{14-16}$. Detailed comparisons of HBS versus individual data in the UK will be reported in a separate paper.

The NFS and the FES have been combined under the Expenditure and Food Survey. In most instances, NFS data are likely to be relied on for analysis of trends in food consumption over time (by region, income group, household composition, etc.). A better understanding of the underlying causes of the discrepancies between the contributing surveys needs to be provided in order to understand any discontinuity of the data.

\section{Acknowledgements}

This paper contains findings that relate to a Europe-wide study concerning the validity of HBS data (the DAFNE II project ${ }^{1}$ ). We are grateful to the many colleagues involved in this project for their ideas and suggestions during informal presentations of preliminary findings. We would also like to acknowledge the Data Archive at the University of Essex, and the financial support from IKY (Greek State Scholarship Foundation) and the European Union Concerted Action AIR - 2087.

The findings in this report are based on material derived from the Family Expenditure Survey and the National Food Survey. Material from these two surveys is Crown Copyright. It has been made available by the Office of National Statistics (ONS) through the Data Archive, based in the University of Essex. Neither the ONS nor the Data Archive bears any responsibility for the analysis or interpretation of the data reported here.

\section{References}

1 Trichopoulou A. Monitoring food intake in Europe: a food data based on household budget surveys. European Journal of Clinical Nutrition 1992; 46(5): S3-8.

2 Chesher A. Diet revealed? Semiparametric estimation of nutrient intake-age relationships (with discussion). Journal of the Royal Statistical Society 1997; 160(Pt. 3): 389-428.

3 Ministry of Agriculture, Fisheries and Food. Fifty years of the National Food Survey 1940-1990. In: Slater JM, ed. Proceedings of a symposium beld in December 1990, London/Ministry of Agriculture, Fisheries and Food Chairman: RE Mordue. London: HM Stationery Office, 1991.

4 Office of National Statistics. Family Spending. A Report on the 1992 Family Expenditure Survey. London: HM Stationery Office, 1993. 
5 Central Statistical Office. Retail Price Index. London: HM Stationery Office, 1983-1994.

6 Matthews JNS, Altman DG, Campbell MJ, Royston P. Analysis of serial measurements in medical research. British Medical Journal 1990; 300: 230-5.

7 Bland M. An Introduction to Medical Statistics, 2nd ed. Oxford: Medical Publications, 1995.

8 Department of Health and Social Security. Diet and Coronary Heart Disease. Report on Health and Social Subjects No. 7. London: HM Stationery Office, 1974.

9 Department of Health and Social Security. Diet and Cardiovascular Disease. Report on Health and Social Subjects No. 28. London: HM Stationery Office, 1984.

10 Department of Health. Nutritional Aspects of Cardiovascular Disease. Report on Health and Social Subjects No. 46. London: HM Stationery Office, 1994.

11 Trichopoulou A, Kanellou A, Lagiou P, Zintzaras E and the DAFNE I group. Integration of nutritional data based on household budget surveys in European countries. Proceedings of the Nutrition Society 1996; 55: 699-704.
12 Trichopoulou A, Lagiou P, eds. DAFNE I - Methodology for the Exploitation of HBS Food Data and Results on Food Availability in 5 European Countries. Luxembourg: Office for Official Publications of the European Communities, 1997.

13 Trichopoulou A, Lagiou P, eds. DAFNE II - Methodology for the Exploitation of HBS Food Data and Results on Food Availability in 6 European Countries. Luxembourg: Office for Official Publications of the European Communities, 1998.

14 Naska A, Paterakis S, Eeckman H, Remaut AM, Trygg K. Methodology for rendering household budget and individual nutrition surveys comparable, at the level of the dietary information collected. Public Health Nutrition 2001; 4(5B): $1153-8$.

15 Naska A, Vasdekis VGS, Trichopoulou A. A preliminary assessment of the use of household budget survey data for the prediction of individual food consumption. Public Health Nutrition 2001; 4(5B): 1159-65.

16 Becker W. Comparability of household and individual food consumption data - evidence from Sweden. Public Health Nutrition 2001; 4(5B): 1177-82. 